\title{
DISNEY: A EMPRESA QUE (RE)CONTA HISTÓRIAS
}

\author{
BRUNO BARICHELLO \\ CENTRO UNIVERSITÁRIO FRANCISCANO \\ SANTAMARIA, RIO GRANDE DO SUL, BRASIL \\ E-MAIL:BRUNOBARICHELLO@GMAIL.COM \\ ANA LUIZA COIRO MORAES \\ UNIVERSIDADE FEDERAL DE SANTA MARIA \\ SANTA MARIA, RIO GRANDE DO SUL, BRASIL \\ E-MAIL:ANACOIRO@GMAIL.COM
}


Resumo: Este artigo faz parte de uma pesquisa de maior fôlego sobre o uso da autopromoção em publicidade e objetiva investigar o uso da autopromoção em espaços editorais de filmes. Está dividido em quatro partes: A articulação da publicidade com o social; Breve genealogia da comunicação publicitária e suas estratégias; O conceito de ação promocional; e, Disney: uma empresa que re-conta histórias.

Palavras-chave: Publicidade; Autopromoção; Estratégias publicitárias.

\section{DISNEY: LA EMPRESA (RE) CUENTA HISTORIAS}

Resumen: Este artículo es parte de una investigación más amplia sobre el uso de la auto-promoción en la publicidad y tiene como objetivo investigar el uso de la auto-promoción en las películas. Se divide en cuatro partes: La relación de la publicidad con la sociedad; Breve genealogía de la comunicación publicitaria y sus estrategias; El concepto de acción promocional; y Disney: una empresa que dice otra vez sus historias.

Palabras clave: Publicidad; Autopromoción; Estrategias publicitarias.

DISNEY: THE COMPANY THAT (RE)TELLS STORIES

Abstract: This article is part of a longer-term research on the use of self-promotion in advertising and aims to understand the use of self-promotion in editorial spaces movies. It is divided into four parts: The articulation of the advertising with social; Brief genealogy of advertising communication and strategies; The concept of promotional action; and, finally, Disney: a company that recounts stories.

Keywords: Advertising; Self-promotion; Advertising strategies. 


\section{INTRODUÇÃO}

No presente trabalho, a partir da perspectiva da publicidade como parte do sistema social, visualiza-se a sua inserção na fronteira entre a comunicação e a mercadologia (KOTLER, 2003) e procura-se compreender as suas estratégias de ação promocional (CASTRO, 2009), ao utilizar o espaço editorial dos filmes para inserir ações promocionais, ou seja, para praticar o que tem sido chamado de merchandising editorial ou tie-in. O merchandising editorial é utilizado desde os primórdios do cinema, no século XX, quando havia inserção de produtos nas cenas fílmicas (carros, máquinas de lavar, sabão em pó, cigarros, entre outros) com o objetivo de promover as compras.

Segundo Luhmann (2005), o sistema de comunicação vai se constituir num dos sistemas de funcionamento da sociedade, responsável por permitir a inter-relação com o sistema social. Nessa perspectiva, podemos pensar a publicidade como um subsistema da comunicação, dentro de um macrossistema de organização social. A publicidade está na interface entre os subsistemas da comunicação e da economia, mais especificamente do marketing que a estuda como promoção de vendas ou ação promocional.

Além disso, as inovações tecnológicas proporcionadas pelos meios de comunicação à sociedade, especialmente ao longo do século XX, acarretaram transformações não só na essência das relações entre produtores e consumidores de bens. Assim a introdução de um novo meio de comunicação acarreta transformações qualitativas nas relações sociais e nas maneiras de pensar e perceber o mundo. Dessa forma, podemos dizer que as práticas publicitárias acompanham a evolução sociotécnica, existindo uma interação constante entre a produção e o consumo tanto de mercadorias como de suas representações simbólicas.

A publicidade, entendida como um processo comunicativo faz parte do sistema social e pode ser estudada por meio de várias perspectivas teórico-metodológicas tais como: a econômica, pois a publicidade altera a lei da oferta e da procura; a mercadológica, pois a publicidade promove as vendas; a simbólica, pois a publicidade trabalha com o imaginário e seus signos; a vertente dos estudos culturais, que procura articular a publicidade com as práticas de produção e/ou recepção contextualizando-as com a ambiência social.

Existe uma tendência nos dias atuais de procurar sintetizar em um único estudo todo o processo de comunicação e superar a dicotomia que existe 
desde a década de 1950, fundamentada nas pesquisas de Harold Lasswell (1949), que tinham como questão: Quem? Diz o quê? Em qual canal? Para quem? Com quais efeitos? Perguntas que foram responsáveis pela polarização dos estudos da comunicação em estudos da produção (quem), estudos da mensagem (diz o quê), estudos dos meios (em qual canal) e estudos de recepção (para quem e com quais efeitos). Com essa proposta Lasswell (1949) procurava contrapor a teoria hipodérmica, em que os meios de comunicação de massa tinham todo o poder sobre o indivíduo. Seguindo esta tendência, Elisa Piedras (2005) apresentou dissertação junto ao Programa de Pós-Graduação em Comunicação da Universidade Federal do Rio Grande do Sul, propondo o entendimento da construção do fluxo publicitário nas práticas de produção e recepção. Piedras (2005) realizou uma pesquisa importante para o avanço dos estudos teóricos em publicidade, mas ao mesmo tempo colocou em evidência a necessidade de tempo para a realização de uma análise empírica de uma proposta teórica como a sua.

Nesse sentido, Escosteguy (2009) lembra a existência de sucessivos estudos que se sobressaem:

Genericamente, pelo reiterado destaque os usos e apropriações dos textos midiáticos pelo receptor e pela referência constante a tais práticas culturais e sociais que vinculam o âmbito individual com o social, sem a necessária observação das limitações impostas pela estruturação social mais geral e até mesmo pelos próprios textos midiáticos. O que se omite, portanto, são as relações de poder e a regulação das esferas do pessoal e do privado pela própria mídia. Em outros termos, há um apagamento da relação inversa - dos textos midiáticos e das lógicas culturais sobre os receptores (ESCOSTEGUY, 2009, p. 4).

A posição de Escosteguy (2009) é complementada pelo fato de que a relação entre cultura e economia, e vice-versa, fica cada vez mais próxima; fenômeno de que não se pode descuidar e que na publicidade costuma ser foco de atenção por necessidade, já que as atividades publicitárias cumprem um fim econômico e social.

A grande dificuldade, hoje, ainda é articular os estudos de dimensões micro e macro-analíticas e seus aportes teórico-metodológicos, especialmente quando se trata de um trabalho monográfico de final de graduação, que não possui o mesmo tempo de dedicação à pesquisa de uma dissertação de mestrado ou tese de doutorado. Por isso, o exercício metodológico do trabalho 
de final de curso necessita adequar o aporte teórico-metodológico ao tempo disponível para sua realização (que em geral vai de seis meses a um ano).

\section{BREVE GENEALOGIA DA COMUNICAÇÃO PUBLICITÁRIA E SUAS ES- TRATÉGIAS}

A atividade publicitária teve início na Antiguidade Clássica, conforme demonstram as tabuletas descobertas em Pompéia, que são consideradas os primeiros vestígios concretos da comunicação publicitária. Essas tabuletas anunciavam combates de gladiadores e faziam referências às termas existentes na cidade. Até a Idade Média, a comunicação publicitária servia a mercadores e comerciantes, que, anunciavam seus produtos através de palavras e gestos. A utilização de símbolos tem início na Idade Média, quando as casas não possuíam número e as ruas não eram identificadas. Os símbolos começaram a ser utilizados para referenciar o ramo de atividade do comércio. Por exemplo, uma cabra simbolizava uma leiteria e um escudo de armas poderia significar a residência de uma família ou de uma pousada. Foram esses símbolos que deram origem às marcas e logotipos (MALANGA, 1979).

Segundo Neusa Demartini Gomes, a publicidade pode ser definida em um sentido amplo como:

[...] atividade mediante a qual bens de consumo e serviços que estão à venda se dão a conhecer, tentando convencer o público da vantagem de adquiri-los. Portanto, existiu sempre: desde que o homem, artesanalmente, produziu algum bem de consumo e tentou persuadir outro homem a adquiri-lo. A história da civilização registra vários momentos em que se usou esta técnica de comunicação para reforçar (antigos) ou criar (novos) hábitos de consumo. Já a publicidade em seu sentido atual, em troca, tem pouco mais de cem anos. Ela nasceu da industrialização, com o advento da revolução industrial, a produção em série, a urbanização, as grandes lojas de departamentos, os meios de comunicação de massa, os transportes coletivos [...] (GOMES, 2001, p. 115).

No século XV, com a invenção da imprensa, por Gutenberg, houve um incremento na comunicação publicitária, pois surgiram os primeiros panfletos impressos em larga escala. Com o advento da era industrial, a produção em massa e a consequente necessidade de aumentar o consumo dos bens produzidos, a técnica publicitária foi-se aperfeiçoando, passando a ser mais 
Disney: a empresa que (re)conta histórias

persuasiva nas suas mensagens e perdendo o sentido unicamente informativo (MALANGA, 1979).

Com o passar do tempo a publicidade foi acompanhando o desenvolvimento dos meios de comunicação, que servem como veículos da comunicação publicitária, por intermédio de uma busca constante de novas estratégias de comunicação e novas formas de atingir o público.

De um modo geral, a noção de estratégia está relacionada à ação de planejar e executar operações com um fim específico. Segundo Castro (2004):

A estratégia corresponde, em uma primeira dimensão, a um principio de organização, a um exercício do fazer, compreendendo a programação ampla (decisão quanto à construção, circulação de valores) que explora as condições favoráveis para alcançar os objetivos pretendidos [...]. Em outra dimensão, diz respeito à colocação em prática das decisões iniciais, compreendendo o emprego eficaz dos recursos disponíveis, o uso de meios econômicos e simples na obtenção de resultados (CASTRO, 2004, p. 3).

As estratégias comunicativas são aquelas que dizem respeito ao enfrentamento dos interlocutores implícitos no processo comunicacional, em um pacto feito de propostas (feitas pelo emissor) e aceitações ou interpretações (feitas pelo espectador). Ou seja:

No caso específico da publicidade, o pacto se firma entre a empresa anunciante e o público consumidor, o que envolve preliminarmente, por parte da empresa, conhecimento de mercado e domínio pontual da realidade política, social, econômica e cultural em que a proposta vai se realizar [...] (CASTRO, 2004, p. 4).

Por mais autoritária que seja a posição do anunciante, ressalta Castro (2004, p. 4), pela sua condição de propor, de autor, ele "precisa lançar mão de uma outra relação, pelo menos de igualdade junto ao consumidor para obter a sua adesão e o seu consentimento".

Os anúncios publicitários costumam utilizar diversas estratégias como: testemunhos de personalidades, pesquisas comprovando a qualidade dos produtos ou argumentos racionais e emocionais para convencer o consumidor a comprar o produto. Essas estratégias acompanham o contexto social e a natureza dos meios de comunicação de cada época.

A publicidade teve um grande impulso após a quebra da bolsa de New York, em 1929, que foi um marco na introdução de pesquisas para conhecer 
o comportamento do consumidor e aprimorar as estratégias de venda. As pesquisas dessa época acompanham a produção industrializada em massa e são ancoradas em um apelo emocional ou racional e sua repetição. Segundo Lipovetsky (1999, p. 217), nas propagandas dessa época: "Com seus slogans redundantes e explicativos, a sedução via seu império refreado pela preeminência do verossímil, do quantitativo, das virtudes 'objetivas' das coisas".

A partir da segunda metade do século XX, a publicidade sofreu transformações: "É a era da publicidade criativa, da festa espetacular: os produtos devem tornar-se estrelas, é preciso transformar os produtos em 'seres vivos', criar 'marcas pessoa' com um estilo e um caráter” (LIPOVETSKY, 1999, p. 217).

A introdução de cada novo veículo foi trazendo mudanças na forma dos consumidores perceberem o mundo e na forma como os produtos eram anunciados. "Ao longo da era da mídia, a publicidade tem sido um espelho que refletiu o estado da mente do consumidor - a publicidade reflete a vida, pode-se dizer" (JAFFE, 2008, p. 40).

O merchandising teve início no ponto de venda e deslocou-se do local da venda com a introdução de novos meios como o cinema e a televisão, quando passou a fazer parte do próprio espaço editorial. No contexto atual, o merchandising editorial continua sendo uma estratégia válida, e será provavelmente ainda mais valorizada diante da introdução da televisão digital, que suprime o tempo destinado à publicidade entre os programas editorias e dá lugar a ações promocionais desenvolvidas na própria programação, um recurso que começou com o cinema na primeira metade do século passado.

\subsection{0 conceito de ação promocional}

A palavra promoção deriva do termo latino promovere, que significa, em síntese, promover ou ainda, enfatizar, impelir para adiante. A ação de promover aproxima-se da noção de marketing, processo pelo qual uma organização se relaciona com o mercado. A compreensão de promoção no campo acadêmico do marketing é definida por Kotler (2003, p. 30) como a ação de "estimular as pessoas a tomar consciência dos vários produtos e serviços da empresa, interessando-se por eles e comprando-os".

O termo marketing formado de market (mercado) e share (porção, parte, quinhão, fatia) indica, por um lado as iniciativas traçadas por uma empresa para definir estratégias de ação, e, por outro, as práticas concretas 
que envolvem o fluxo de produtos ou serviços entre produtor e consumidor (CASTRO, 2009, p. 1).

O que nos interessa no presente trabalho monográfico é o que Castro discute a respeito do conceito de ação promocional em uma dimensão ampla, principalmente no sentido de compreender as ações que correspondem ao planejamento de ações estratégicas até chegar ao plano da realização, da concretude da produção. A pesquisadora amplia o conceito de ação promocional proposto por Kotler (2003) e analisa suas funções estratégicas. Segundo Castro (2009):

Do latim promovere, promoção significa elevação, impulsão para frente, engrandecimento. Segundo Houaiss, envolve "qualquer atividade (de propaganda, marketing, divulgação, relações públicas etc.) destinada a tornar mais conhecido e prestigiado um produto, serviço, marca, idéia, pessoa ou instituição". Nessa medida, a promoção comporta o movimento para frente, no sentido de divulgar, de projetar, de tornar conhecido alguém ou alguma coisa por suas ações, atributos (CASTRO, 2009, p. 3).

A concepção de ação promocional, proposta por Castro (2009), difere do pensamento de Kotler (2003), que vê a promoção apenas como uma das habilidades do marketing, com o objetivo de estimular as pessoas a tomarem consciência dos vários produtos e serviços da empresa, induzindo-as à compra. Já que Castro (2009) situa a promoção além do interesse de compra, pois inclui um espaço de projeção para quem nela se mostra, ou seja, a autopromoção.

Conforme Castro (2010, p. 3), "centrada nos próprios processos e produtos, essa fala de si mesma, em termos de conteúdo, compreende o processo comunicativo" que na televisão, inclui os programas ofertados, o crescimento tecnológico da emissora, o comando diretivo da empresa, as ações sociais que desenvolvem, os atores e personagens de seus programas.

Essa constatação da autopromoção na televisão, destacada por Castro, pode ser utilizada para a análise da autopromoção de produtos e personagens no cinema, especialmente nos filmes da Disney, já que o objeto de estudo deste trabalho é a autopromoção nos filmes da empresa. Esse movimento de promoção está relacionado com a busca de fortalecimento da marca, pois: 
Nessa perspectiva, o discurso da promoção, em consonância com a marca, concentra (1) a necessidade constante de, com a evolução dos comportamentos de consumo, variar suas mensagens, para atingir públicos mais específicos; (2) a diversificação de instrumentos, mudando o discurso de acordo com o suporte escoIhido; e (3) a vontade de estreitar os laços com os destinatários, resultando em ações sistemáticas, direcionadas à divulgação dos produtos da emissora e, também, à propagação de sua marca e imagem (CASTRO, 2010, p. 4).

Castro (2010, p. 4) explicita a especificidade da estratégia promocional quando descreve que "dois movimentos fundam sua ação [a ação promocional]: aquele que recorre ao discurso pré-existente a ele, do qual ele fala; e aquele que implica a presença de um segmento que faça de si próprio objeto do discurso por ele mesmo produzido". Segundo a pesquisadora gaúcha, a ação promocional centra-se basicamente na articulação desses movimentos:

[...] na medida em que os produtos produzidos mesclam a recorrência a produtos, em nítida relação intertextual com aqueles já, temporalmente, veiculados, com a fala de si mesma, reforçando o próprio processo comunicativo, as tecnologias utilizadas, as ações em sociedade, os atores e personagens dos programas da emissora (CASTRO, 2010, p. 4).

A pesquisadora explica, ainda, que o resultado desses movimentos de autopromoção, que, tanto referenciam produtos antigos em novos produtos, como promovem a própria marca, é:

[...] a complexa e variada presença de produtos com a assumida configuração promocional, que se apresentam de forma explícita ou sutil, caracterizando, no caso deste último, a operação de deslocamento, pelo fato de tentar levar o consumidor a agir por impulso, afastando dele o conhecimento racional, o espírito crítico, para centrar-se na dimensão emocional, que tem a ver com aceitação e/ou adesão inconteste (CASTRO, 2010, p. 5).

$\mathrm{Na}$ área de publicidade a ação promocional pode estar associada ao tie-in, ou seja, a uma estratégia de merchandising, na qual produtos, marcas ou serviços são inseridos em meios eletrônicos como a televisão e o cinema. As imagens de produtos ou personagens, inseridas no espaço editorial da programação da televisão ou, ainda, no espaço editorial de um filme, podem 
ocorrer de forma mais explícita ou mais sutil, e, no caso das aparições sutis, quase imperceptíveis, podem configurar um apelo emocional da divulgação publicitária sob a forma de autopromoção.

Uma empresa cinematográfica, ao inserir mensagens em um filme remetendo a outras produções que fazem parte de seu acervo, está se autopromovendo e utilizando o espaço editorial do filme. Esse tipo de técnica chama-se tie-in, palavra de origem inglesa que significa conexão ou, em outras palavras, relação.

A inserção de mensagens pode ser feita também com a técnica de cameo appearance, que significa aparência camuflada, e que tem sido utilizada desde o início da indústria cinematográgica para promover personagens em rápidas aparições em meio a um filme.

Conforme Sampaio (2003), as mídias conhecidas como tradicionais podem ser classificadas em duas categorias: mídia eletrônica e mídia impressa. O autor comenta, ainda, que o cinema é tratado pelo mercado como mídia eletrônica. Em termos publicitários, pode-se dizer que o presente estudo trata da ação promocional como estratégia publicitária em uma mídia eletrônica, o cinema.

\subsection{Disney: uma empresa que (re)conta histórias}

A trajetória da empresa Walt Disney Productions e de seu criador, Walt Disney, relatada a seguir, está embasada nos seguintes livros: "O mundo da Disney" (MOYA, 1996), que retrata a trajetória da empresa em um sentido biográfico; "Disneywar", que analisa as estratégias da Disney como empresa de entretenimento (STEWART, 2006); “Walt Disney” (EISENSTEIN, 2004), que é a biografia de Walt Disney escrita pelo grande cineasta russo Eisenstein; "Cinema: arte \& indústria" (ROSENFELD, 2002) e "O cinema de Hollywood" (PARAIRE, 1994). As duas últimas obras abordam o contexto da Disney na indústria do cinema.

A utilização do desenho animado pelo cinema tem em Walt Disney um de seus maiores expoentes, senão o maior, embora a animação como narrativa cinematográfica tenha sido inventada por Émile Cohl, que teve a ideia de transformar caricaturas em protagonistas de filmes fotografando séries de desenhos (ROSENFELD, 2002).

Eisenstein (2004, p. 13) inicia seu livro sobre Walt Disney com a seguinte 
frase: "a obra deste mestre é a maior contribuição do povo Americano para a arte - um aporte imenso dos americanos para a cultura mundial" [Grifo do autor $]^{24}$.

Foi com Disney que a animação ganhou elementos inovadores, tais como: a animação total (todas as partes do corpo se mexem), o uso precoce da cor, um cuidado extremado com os desenhos, uma pesquisa permanente de novos rostos e de roteiros adaptados ao seu público infantil (PARAIRE, 1994).

Walt Elias Disney Junior nasceu em Chicago, no dia 5 de dezembro de 1901, em uma casa situada no número 1249 da Tripp Avenue. Logo depois de seu nascimento, a família se transferiu para o interior, em uma pequena fazenda em Missouri, onde Walt passou quatro anos de sua infância, que o marcaram muito e constituem a base das cenas bucólicas de suas obras. Ele é o quarto filho de Elias Disney e Flora Call, antecedido por Herbert, Raymond e Roy. Em 1910 a família Disney transferiu-se para Kansas City (POMA$\mathrm{TI}, 2004)$.

Ainda, segundo Pomati (2004), em junho de 1917, quando terminou seus estudos secundários, Walt decidiu dedicar-se à carreira de cartunista.

Aos 16 anos já possuía as qualidades que o levariam ao sucesso: um discreto talento como desenhista, um sentido inato do espetáculo, uma bagagem cultural de poucas mas boas leituras (Mark Twain, Walter Scott, Stevenson, Dickens), a experiência de uma vida no interior que Ihe inspira a poesia das pequenas coisas que tanto agradam ao público médio norte-americano, um certo espírito de aventura, sólidas raízes no ideal patriótico, o gosto pelo desafio, à vontade de fazer, a vontade de afirmar-se (POMATI, 2004, p. 117$)^{25}$.

Em 1918 seus pais transferiram-se, novamente, para Chicago, onde Walt se inscreveu no curso de desenho do Instituto de Artes de Chicago. Pouco mais tarde tentou alistar-se no exército americano, para acompanhar seus irmãos mais velhos e foi aceito como motorista de ambulâncias da Cruz Vermelha na França, durante a Primeira Guerra Mundial. Ao retornar aos Estados Unidos, um ano depois, passou a morar em Kansas com seu irmão

24 Tradução livre do autores.

25 Tradução livre do autores. 
Roy e a trabalhar como estagiário na Agência Publicitária Pesmen-Rubin Art Studio. Foi nessa época que Disney aprendeu os princípios técnicos básicos do desenho animado e fez amizade com Ub Iwerks, um jovem e talentoso desenhista. Os dois decidiram sair da empresa de publicidade e fundar uma pequena empresa, a Iwerks-Disney Commercial Artists, que teve uma vida muito breve, mas não atrapalhou a amizade entre Walt e Ub. Walt passa a trabalhar para uma companhia cinematográfica, a Kansas City Film Art, que produzia curtas metragens de desenhos animados para serem exibidos antes do filme principal (EISENSTEIN, 2004).

A partir dessa aproximação com a indústria cinematográfica, teve a iniciativa de criar, com o irmão Roy Disney e o amigo Ub Iwerks, uma pequena produtora, a Laugh-O-Gram, que animava contos infantis em filmes de curta duração exibidos nas salas de cinema antes dos filmes de longa metragem.

Em 1923, mudou-se para Los Angeles, onde continuou a produzir animações. Ainda no ano de 1923 produziu a série Alice Commedies, na qual uma atriz contracenava com personagens animados em um ambiente de animação. A série fez sucesso e o estúdio de Disney ficou conhecido; mas, com a diminuição da popularidade da série a produtora mudou-se para Nova York e assinou contrato com uma distribuidora de filmes. Em Nova York, o primeiro projeto foi o coelho "Oswald", cujos episódios passaram a ser exibidos em salas de cinema antes do filme principal. Foi nessa época que Disney conheceu a animadora Lílian Bounds, com quem se casou, em 1925, e teve duas filhas, Diane Marie e Sharon Mae.

A criação do camundongo Mickey, em 1928, marcou a consolidação da empresa e do primeiro personagem com efetivo sucesso. A partir desse marco a empresa também passou a ser mais bem organizada: o irmão Roy cuidava das finanças, Walt Disney produzia e dirigia e o amigo Iwerks desenhava.

No início era o próprio Walt que dublava Mickey. Depois surgiram outros personagens para contracenar com o camundongo: Pato Donald, Pateta e Pluto. Nesse período, foi criado o filme Branca de Neve e os Sete Anões, que é considerado um marco na história da animação.

Nos anos de 1930 os estúdios da Disney cresceram muito, apesar da crise econômica que os Estados Unidos estavam atravessando. Em 1932 a Disney produziu o primeiro curta metragem em desenho animado a cores, Flowers and Trees, que foi premiado com o primeiro dos 32 prêmios Oscar ganhos pela empresa. 
Os Estúdios Disney estavam sempre inovando e experimentando novas técnicas de vanguarda, como a câmera multiplano (multiplane câmera), que contribuiu para a realização do maior desafio que os Estúdios Disney haviam enfrentado até então: a realização do filme Branca de Neve e os Sete Anões, o primeiro longa metragem em desenho animado da história do cinema.

Conforme Pomati (2004, p. 124):

Na mente do grande Walt tudo era possível, mas para os seus colaboradores o projeto inteiro parecia loucura pura [...] Walt Disney foi o motor de tudo e seguiu cada detalhe [...] Graças a um talento dificilmente mensurável, a dois milhões de desenhos, a três anos de trabalho de trinta e dois animadores, e a um milhão e meio de dólares ou talvez um pouco mais [...] a 'loucura de Walt Disney', para citar um parecer emitido em seu tempo, deu ao mundo uma das obras primas absolutas do cinema [...] (POMATI, 2004, p. $124) .{ }^{26}$

O primeiro longa metragem em desenho animado foi premiado com um Oscar especial,

[...] pela indiscutível inovação no campo cinematográfico e por haver fascinado milhões de espectadores e aberto ao cinema horizontes mais vastos, Branca de Neve e os Sete Anões é também a síntese do estilo Disney, da sua filosofia artística e do seu feliz tino comercial (POMATI, 2004, p. 125) 27.

A inauguração da nova sede da Walt Disney Studios, em 1940, coincidiu com uma nova fase de produção de filmes longa metragem, como Pinóquio, Bambi e Fantasia, sendo este último o primeiro filme a utilizar o som estereofônico. Hoje considerados sucessos da Disney, os três filmes na época foram desastres de bilheteria e sofreram fortes críticas.

Nos anos do pós-guerra os estúdios trabalharam quase que exclusivamente para o governo norte-americano, produzindo curtas metragens para as Forças Armadas. Ainda nos anos de 1950, os estúdios Disney decidiram arriscar-se na televisão, ao mesmo tempo em que produziam novos longas metragens baseados em histórias infantis clássicas: Cinderela, Alice no País das Maravilhas e Peter Pan. Cinderela foi um sucesso de bilheteria e auxiliou

Tradução livre dos autores.

27 Tradução livre dos autores. 
Disney: a empresa que (re)conta histórias

a empresa a reestruturar as suas finanças.

\section{CONSIDERAÇÕES}

A relação de Walt Disney com a publicidade está presente desde a sua juventude, fato que provavelmente tenha influenciado a sua capacidade de promover os seus empreendimentos e suas obras cinematográficas utilizando-se do espaço editorial de um filme para promover outros produtos e reforçar a própria marca Disney.

Walt Disney foi um dos primeiros produtores de cinema norte-americano a entender a importância da televisão, como um instrumento para aproximar as novas gerações de suas produções e atuar como um extraordinário veículo publicitário para os seus filmes, assim como para os produtos ligados aos personagens da Disney. Graças à televisão e, em especial, à colaboração com a rede $A B C$, Disney promoveu e financiou, em grande parte, o projeto do parque temático Disneylândia, inaugurado em 1955, na Califórnia. Após a morte de Disney, foi inaugurado um novo parque de diversões, a Disneyword, na Flórida, em 1971.

Disney faleceu em 15 de dezembro de 1966 e seu legado permanece até hoje, graças à atuação de sua mulher Lillian Bounds, das filhas Diane Marie e Sharon Mae e de seu irmão Roy, que continuaram dirigindo a empresa. $O$ empresário transformou-se em um mito do desenho animado e criou, com a ajuda de seus personagens, todo um universo de referências no imaginário infantil de várias gerações, sendo considerado um dos maiores diretores de cinema de todos os tempos.

Segundo Conter e Silva (2006), já no filme Fantasia da Disney, de 1940, são encontradas estruturas que se repetirão nas demais décadas, ou seja, em muitas cenas ocorrem traduções intersemióticas, que consistem em produzir, reinventar e/ou adicionar outra forma, outro conceito, uma outra expressão a uma proposta original.

A estratégia de re(contar) histórias ou re(apresentar) personagens é utilizada como um álibi para a autopromoção nas obras da Disney. 


\section{REFERÊNCIAS}

CASTRO, Maria Lilia Dias de. Nos bastidores do entretenimento: ação promocional. Trabalho apresentado no GT Mídia e entretenimento. In: ENCONTRO DA COMPÓS, 19. ed., 2010, Rio de Janeiro (RJ). Anais..., PUCRio, Rio de Janeiro (RJ), COMPÓS, 2010.

. Movimento Promocional: falar de si para poder falar dos outros. Trabalho apresentado no GT Mídia e entretenimento. In: ENCONTRO DA COMPÓS, 18. ed., 2009, Belo Horizonte (MG), Anais... Belo Horizonte (MG), COMPÓS, 2009.

. Lógicas e estratégias em publicidade. Trabalho apresentado no NP Publicidade, Propaganda e Marketing. In: CONGRESSO BRASILEIRO DE CIÊNCIAS DA COMUNICAÇÃO, 27. ed., 2004, Porto Alegre. Anais... São Paulo (SP), Intercom, 2004.

CONTER, Marcelo B; SILVA, Alexandre Rocha da. Aprendizes do Fantasia. Revista Sessões do Imaginário, Porto Alegre, p.56-62, 2006.

EISENSTEIN, Serguei. Walt Disney. Milano, Itália: SE, 2004.

ESCOSTEGUY, Ana Carolina. Quando a recepção já não alcança: os sentidos circulam entre a produção e a recepção. Revista da Associação Nacional dos Programas de Pós-graduação em comunicação. E-Compós, Brasília, vol. 12, n.1. jan-abr., 2009.

GOMES, Neusa Demartini. Publicidade ou propaganda? É isso aí! Revista FAMECOS, Porto Alegre, $n^{\circ} 16$, dezembro 2001, p 111-121.

JAFFE, J. O declínio da mídia de massa: por que os comerciais de TV de 30 segundos estão com os dias contados. São Paulo: M. Books, 2008.

KOTLER, P. Marketing de A a Z. 4.ed. Rio de Janeiro: Elsevier, 2003.

LASSWELL, Harold D. The Structure and Function of Communication in Society. New York: Harpers and Brothers, 1949.

LIPOVETSKY, Gilles. O império do efêmero. São Paulo: Cia das Letras, 1999.

LUHMANN, N. A realidade dos meios de comunicação. São Paulo: Paulos, 2005.

MALANGA, Eugênio. Publicidade: uma introdução. Atlas, São Paulo, 1979.

MOYA, Álvaro de. O mundo da Disney. São Paulo: Geração Editorial, 1996.

PARAIRE, Philippe. O cinema de Hollywood. São Paulo: Martins Fontes, 1994.

PIEDRAS, Elisa. A articulação da publicidade com o mundo social: a constituição do fluxo publicitário nas práticas de produção e recepção. Dissertação (Mestrado). Programa de Pós-graduação em Comunicação e informação. UFRGS. 2005

POMATI, Sergio. L'uomo che vole farsi re (di cartoonia) vita e magie di Walt Disney In: EISENSTEIN, Serguei. Walt Disney. Milano, Itália: SE, 2004.

ROSENFELD, Anatol. Cinema: arte \& indústria. São Paulo: Perspectiva, 2002.

SAMPAIO, Rafael. Propaganda de A a Z. Campus: Rio de Janeiro, 2003.

STEWART, James B. Disneywar. Rio de Janeiro: Ediouro, 2006. 
Disney: a empresa que (re)conta histórias

\section{Bruno Barichello}

Aluno da Universidad de La República (Uruguay)

Publicitário e Jornalista - Centro Universitário Franciscano (UNIFRA).brunobarichello@gmail.com

\section{Ana Luiza Coiro Moraes}

Doutora em Comunicação pela PUCRS, Pós-Doutora pela UFBA, Professora Colaboradora do Programa de Pós-Graduação em Comunicação da UFSM. anacoiro@gmail.com 
RECEBIDO EM: 15/11/2015

APROVADO PARA PUBLICAÇÃO: 20/11/2015 